\title{
Urban Growth: From pixel to reality
}

\author{
Shyamantha Subasinghe ${ }^{a^{*}}$ \\ ${ }^{a}$ Department of Geography, University of Peradeniy, Peradeniya 20400, Sri Lanka
}

Keywords: Spatial Pattern Recognition, Geo-visualization, Neighborhood interaction

\begin{abstract}
:
Urban growth is a complex process created through the interaction of human and environmental conditions. The spatial configuration and dynamic process of urban growth is an important topic in contemporary geographical studies (Thapa and Murayama, 2010). However, urban growth pattern recognition is a challengeable task and it has become one of the major fields in Cartography. Since classical era of cartography, several methods have been employed in modelling and urban growth pattern recognition. It shows that there is no agreement among cartographer or any other spatial scientists on how to map the diverse patterns of urban growth.
\end{abstract}

Typical urban theories such as von Thünen's (1826) bid-rent theory, Burgess's (1925) concentric zone model, Christaller's (1933) central place theory, and Hoyt's (1939) sector model explain the urban structure in different manner. Most of them do not contribute to visualize the urban growth pattern spatiotemporally. Recently, by addressing this limitations, several sophisticated methods are used in urban growth visualization. Among them, morphological spatial pattern analysis (MSPA) is one of emerging raster data analysis methods which allows us to integrate neighbourhood interaction rules in urban growth pattern recognition and visualization. Angel et al. (2010) developed urban land classification (urban, suburban, rural, fringe open space, exterior open space, and rural open space) based on built and non-built land categories and detected three major types of urban growth (infill, extension, and leapfrog). However, developing urban land classifications using binary land use type and recognising only three types of urban growth pattern may be insufficient due to the existence of a higher complexity of urban growth. In such context, the present study introduce a geovisualization approach to map spatial patterns of urban growth using multiple land categories and develops three sub-levels of urban growth pattern for each major urban growth pattern.

The entire process of urban growth pattern recognition developed in this study can be summarized into three steps (Figure 1): (1) urban land mapping-Landsat imageries representing two time points (2001 and 2017) were classified into two land categories (built and non-built) and developed into multiple classes using ancillary data, (2) recognizing three major patterns of urban growth (infill, extension, and leapfrog) - the raster overlay method based on neighbourhood interaction rules, (3) development of sublevels of urban growth - major three patterns were further developed and visualized nine urban growth patterns, namely low infill (LI), moderate infill (MI), high infill (HI), low extension (LE), moderate extension (ME), high extension (HE), low leapfrog (LL), moderate leapfrog (ML), and high leapfrog (HL). The developed procedure of this study in urban growth pattern recognition was tested using a case study of Colombo metropolitan area, Sri Lanka.

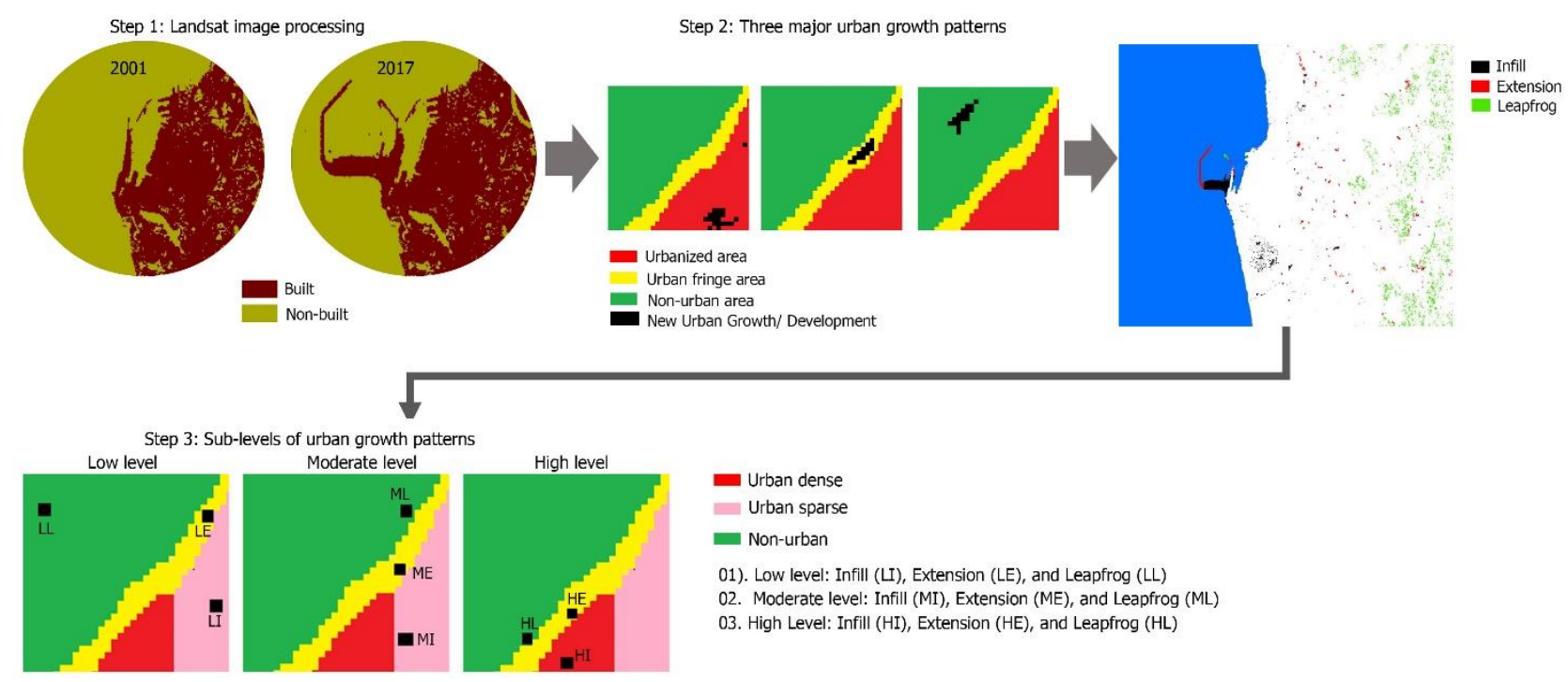

Figure 1: Process of Urban growth pattern recognition 